Motrivivência $\quad$ Ano XXIV, № 38, P. 231-246 Jun./2012

\title{
AMPLIANDO O OLHAR SOBRE SAÚDE NA EDUCAÇÃO FÍSICA ESCOLAR: críticas e possibilidades no diálogo com o tema do meio-ambiente a partir da Saúde Coletiva ${ }^{1}$
}

Cristiano Mezzaroba²

\section{RESUMO}

Este texto propõe uma reflexão em torno das questões da saúde na Educação Física escolar (EFE), ampliando o olhar para essa relação histórica e que merece, em nosso tempo presente, considerações mais aprofundadas aos professores de EF e que ultrapassem o plano unicausal, por exemplo, a ideia de que a atividade física gera saúde automaticamente. Aborda-se tal problemática a partir do referencial da "saúde coletiva", numa tentativa de aproximação dos elementos da EF com as Ciências Sociais/Humanas, apresentando algumas implicações para a EFE, principalmente, a mudança de enfoque/ paradigma, saindo do plano patogênico em direção às possibilidades com a salutogenia.

Palavras-chave: Saúde; Educação Física escolar; formação profissional na Educação Física.

1 Texto didático elaborado para a disciplina Saúde, Sociedade e Educação Física do curso de Licenciatura em Educação Física da Universidade Federal de Sergipe. Produzido em maio de 2010 e, desde então, reorganizado a partir das experiências de ensino semestralmente.

2 Mestre em Educação Física pela Universidade Federal de Santa Catarina. Professor do Departamento de Educação Física (DEF), do Centro de Ciências Biológicas e da Saúde da Universidade Federal de Sergipe. Pesquisador e Coordenador do LaboMídia/UFS. Contato: cristiano_mezzaroba@yahoo.com.br. 
PALAVRAS INICIAIS E CONTEXTUALIZAÇÃO DO DEBATE

Refletir sobre temas tão atuais e, ao mesmo tempo tão necessários, como o meio ambiente e saúde é um exercício que pressupõe à comunidade da Educação Física (EF), especialmente aqueles que têm como foco a área escolar, a "quebra" do paradigma hegemônico da saúde ${ }^{7}$ e uma (re)organização dos saberes e práticas em direção à chamada "saúde coletiva".

Tal visão que procurarei argumentar neste meu exercício reflexivo considerará o atual paradigma da sustentabilidade, bastante comentado atualmente, referindo-se aos problemas ambientais que o mundo todo vem enfrentando em decorrência do nosso modo de produção capitalista em que tudo se transforma em mercadoria, inclusive o próprio "estilo de se viver", além das degradações que ocorrem nos âmbitos ambiental e social.

Lançarei mão, para isto, de uma aproximação com as Ciências Humanas e Sociais (História, Sociologia, Antropologia, Filosofia) apoiando-me em referenciais teóricos críticos, os quais procurarão considerar o tema do meio-ambiente e da saúde em relação à EF escolar, fazendo uma abordagem histórica das determinações do processo saúde-doença, chegando aos elementos teórico-conceituais da Saúde Coletiva $^{8}$ e as possíveis implicações disso tudo no campo da EF escolar, vista, conforme penso, como um campo de intervenção pedagógica (BRACHT, 1999), em que o professor de EF se apropria, constrói e media conhecimentos das mais variadas "ciências", na tentativa de tornar seus alunos críticos, autônomos e cidadãos, sabedores de seus direitos e não meros praticantes ou prescritores de atividades físicas descontextualizadas.

É necessário deixar claro, desde já, que tais reflexões referem-se à preocupação com a formação de professores de Educação Física, e para isso, corroboro às idéias de Schon (1992) citado por Rodrigues (1998), que fala sobre o "professor reflexivo", ou seja, aquele que, para além dos seus conhecimentos técnicos/teóricos/pedagógicos, exerce a reflexão como crítica constante no seu trabalho pedagógico, seja nas dimensões do "conhecimento na ação" (saber fazer), da "reflexão na ação" (pensar sobre) e a "reflexão sobre a ação e a reflexão na ação" (reflexão como auto-crítica).

Ao se falar sobre a formação de professores de EF, devemos considerar também as condições históricas que esta disciplina carrega consigo, principalmente em relação

7 Refere-se ao modelo no qual, historicamente, configurou a EF, ou seja, a influência médica e o desenvolvimento da Fisiologia, via desenvolvimento da aptidão física, baseando-se principalmente nos benefícios orgânicos causados pelo exercício visando à saúde (GUEDES, 2000). Foi no início dos anos 1980 que surgiu em países como a Grã-Bretanha, Canadá, Estados Unidos e Austrália um movimento chamado "Aptidão Física Relacionada à Saúde - AFRS", cuja proposta seria contribuir na formulação das Diretrizes Curriculares Nacionais destes países, definindo que o currículo nacional de EF objetivasse principalmente a aptidão física relacionada à saúde, oferecendo aos alunos conhecimentos dos benefícios da prática regular do exercício físico. (FERREIRA, 2001)

8 Em Gonçalves (2004), o autor argumenta que a construção do conhecimento na EF brasileira evoluiu consideravelmente nos últimos anos, entretanto, uma de suas dimensões, a da "saúde", permaneceu de certa maneira intocada. Segundo tal autor, "permanece intocado o paradigma mecanicista, que trata fragmentadamente os conhecimentos gerados na área da saúde relacionada à atividade física." (p.90) 
às questões higienistas ${ }^{9} \mathrm{e}$ a influência médica $^{10}$ que outrora dominavam-na e que hoje voltam à tona no chamado movimento da "saúde renovada", preocupada com a assepsia social.

Como o tema desta reflexão associa-se às questões do meio ambiente, considero importante enfatizar que o enfoque não deve privilegiar apenas os aspectos ligados à natureza (ou às questões físicas e naturais), mas sim entender o meio ambiente como o lugar e o meio que os homens vivem, compartilham e transformam sua vida, portanto, uma visão mais "macro", no sentido de "sociedade"11, com ênfase nas determinações sociais ${ }^{12}$.

Isso possibilita que tenhamos uma visão histórica e sociológica das repercussões na relação dos indivíduos em seu conjunto (sociedade) com o que hoje se considera como a determinação social da saúde (GONÇALVES, 1997; ZIONI, WESTPHAL, 2007), passando-se da teoria dos miasmas à teoria bacteriológica e destas ao modelo atual, que considera as doenças crônico-degenerativas como o problema do mundo todo a ser enfrentado.

Nos últimos tempos, o mundo mudou. De uma sociedade feudal/rural, passamos - não por mera transposição histórica ou um "acontecimento mágico" ao que se configura como a sociedade urbano-industrial, marcada pela máquina/indústria, pela tecnologia, pela mão-de-obra especializada, pelo conhecimento científico, pelas transformações de se viver em grandes cidades, gerando formas variadas de sociabilidade e de convívio não só com as outras pessoas, mas com os problemas que decorrem deste "movimento moderno de viver".

Refiro-me, especialmente, à urbanização e seus problemas, fenômeno que se iniciou ainda no século XVIII, com a Revolução Industrial inglesa, mas que a partir da segunda metade do século XX espalhou-se pelo mundo todo e trouxe consigo, além do desenvolvimento econômico, social e científico (principalmente nos países ricos), problemas ambientais e sociais (em grande maioria nos países mais pobres).

9 Segundo Soares (2007), a EF era (e ainda é) entendida como "cuidado com o corpo", a fim de resolver os problemas da sociedade industrial. Para esta autora, "A Educação Física construída por uma sociedade naturalizada e biologizada será então tomada como a 'educação do físico', e associada diretamente à saúde do 'corpo biológico' (leia-se social). Os médicos higienistas, imbuídos da certeza de que detinham uma maior competência para redefinir os 'hábitos' da família moderna, não poderiam deixar de influenciar de maneira decisiva o referencial de conhecimentos necessários para o desenvolvimento da Educação Física, um mecanismo a mais utilizado na construção do homem novo, este sujeito do capital." (SOARES, 2007, p.32)

10 Conforme Darido (2001), essa influência médica apresenta-se no próprio caráter histórico dos conteúdos de EF considerando-se o contexto brasileiro, naquilo que se convencionou chamar de higienismo, e que hoje se manifesta, por exemplo, no chamado "movimento da saúde renovada". (GUEDES; GUEDES, 1993a, 1993b, 1994a, 1994b; NAHAS, 2003). Sobre isso, Farinatti \& Ferreira (2006) consideram que: “(...) Ainda hoje, essa relação entre educação física e saúde está presente no discurso oficial, uma vez que os Parâmetros Curriculares Nacionais apresentam a saúde como tema transversal a ser desenvolvido pela educação física escolar no terceiro e quarto ciclos do ensino fundamental. (...) A tônica na saúde, via aptidão física, também é observada no discurso profissional da disciplina; a aptidão física é apontada como um de seus objetivos básicos.

11 Giddens (2005) auxilia-nos nessas reflexões em torno do processo saúde-doença sob o ponto de vista sociológico. Trata das questões da doença à saúde; do hospital à comunidade; da cura à prevenção; da intervenção ao monitoramente; do tratamento ao cuidado; do paciente à pessoa.

12 Segundo Palma (2000), devemos considerar que os efeitos das desigualdades sociais sobre a saúde são produto do processo histórico-político-econômico, o qual reflete a combinação de exposições negativas, perda de recursos, dificuldade de acesso aos serviços, deficiências de informação, entre outros. 
A princípio, na visão hegemônica de saúde e no tipo de "pensamento hegemônico" (ou estilo de pensamento ${ }^{13}$, segundo BESEN et al, 2007) da formação em EF, poderia-se pensar: mas o que isso tudo tem a ver com Educação Física? Não estamos "fugindo" de nosso foco?

Na sequência do texto faremos o esforço de ampliar o olhar a todas essas questões, na tentativa de apresentar as críticas a essa relação entre EF e saúde (quando vista com os "óculos do reducionismo"), bem como possibilidades que a EFE tem no trato pedagógico ao tematizar tais questões (com as "lentes da saúde coletiva e de uma EF crítica").

\section{EDUCAÇÃO FÍSICA E SAÚDE: aproxi- mando-se e tornando a discussão mais complexa}

Acreditando na perspectiva da interdisciplinaridade (MINAYO, 1994; CARVALHO, 2001), penso que a EF pode e deve ampliar sua visão, o seu olhar sobre os mais variados aspectos, entre eles, o ambiental e não reduzir-se, como é de costume e estão tão na moda, às questões individuais dos "estilos de vida"14, pois estes estão profundamente ligados ao individualismo e dizem respeito a uma camada da população de classe média e alta que, por suas condições de vida, conseguem o acesso a práticas corporais mais diversas (diferentemente da grande maioria da população, pobre, diga-se, em que o acesso a tais práticas perde-se de vista na sua lista de prioridades).
Sob este entendimento, mais amplo em relação às questões ambientais, há que se considerar, por exemplo, outras variáveis, como: moradia, saneamento básico e esgoto, alimentação/nutrição, o trabalho, a renda, o lazer, as práticas corporais, o acesso aos serviços de saúde, entre outros. (BAGRICHEVSKY, ESTEVÃO, PALMA, 2003; 2006; 2007)

Como se percebe, configura-se uma visão de saúde que ultrapassa àquela da própria Saúde Pública, que costuma reforçar a ideia de que o indivíduo é responsável pela degradação de sua qualidade de vida. Segundo Carvalho (2009, p.168), sob o ponto de vista da Saúde Pública:

(...) as enfermidades são causadas pela negligência do indivíduo com relação ao seu corpo. Está constantemente lembrando à população o seu compromisso com os cuidados alimentares, o excesso de bebida, o fumo e a necessidade de atividade física para promoção da saúde.

Os indivíduos são afetados pelos mais diversos problemas no que se refere ao ambiente em que vivem, como por exemplo, a violência ${ }^{15}$ urbana (com os problemas, acidentes e mortes no trânsito das cidades), os homicídios, o narcotráfico, a poluição do ar, das águas, sonora, entre outros tantos problemas.

Defender o discurso de que "exercício é saúde" em determinado contexto sociocultural pode ser um grande equívoco por parte de professores de EF, já que este discurso que liga a causa (fazer atividade

13 Estilo de pensamento (EP) se refere aos "modos de ver, entender e conceber, que levam a um corpo de conhecimentos e práticas compartilhados por um coletivo com formação específica." (BESEN et al, 2007, p.58)

14 Sobre isso, ver mais em Fraga (2006) e Gomes (2009).

15 Há uma publicação, datada de 2005, do Ministério da Saúde (Brasil), intitulada Impacto da violência na saúde dos brasileiros que apresenta textos diversos e interessantes sobre a temática. (BRASIL, 2005) 
física) a um efeito (gerar saúde), o conhecido discurso da causalidade, é algo reducionista e problemático ${ }^{16}$.

Como, por exemplo, alguém que reside em áreas de alto índice de violência pode sair de sua casa e praticar atividade física, ficando exposto a agravos? Até que ponto há espaços de lazer para a população em geral realizar suas atividades corporais? Como associar "saúde" ao "exercício físico" quando este é realizado em locais de grande poluição do ar? As atividades físicas prescritas num programa de televisão ou mesmo sugeridas nas páginas de uma revista, ao alcançar uma massa de receptores, de que forma ultrapassam as barreiras dos limites da individualidade biológica? As necessidades e os gostos de cada sujeito, como são articuladas quando o discurso surge e se dissemina de maneira unívoca?

Carvalho (2009) trata dessa relação entre a atividade física (defendida por grande parte do campo da EF como "remédio" e como "vacina" atualmente) e saúde como se fosse um "mito". Para essa autora,

(...) Uma vez que o 'mito' compõe nosso cotidiano, sinalizando determinada compreensão da realidade - 'sem necessidade de provas' - , ele assume a função de 'modelar' o indivíduo e não de interpretar, explicar os fatos. E assim o 'mito' atividade física e saúde ganha 'forma'. Todavia, uma análise crítica a respeito do 'mito' da atividade física e saúde, conhecê-lo, pensá-lo, ter a consciência de sua existência pode devolver a posse e a guarda de corpos e mentes aos indivíduos. (CARVALHO, 2009, p.171-2).
Farinatti \& Ferreira (2006) também trazem questionamentos quanto a tais questões. Questionam sobre a atual corrida em busca de saúde, no sentido de quais pessoas que dispõem de recursos financeiros para frequentar academias e de quais pessoas ficam alijadas da prática regular de atividade física; se ter uma vida fisicamente ativa depende exclusivamente da opção do indivíduo ou existem determinações sociais em torno desta questão - enfim, reflexões que mostram que o acesso à prática de atividades físicas dizem respeito às desigualdades em nossa sociedade.

De maneira geral, poderíamos sintetizar que a relação entre atividade física e saúde, conforme defendida pelo campo hegemônico da $E F$, pode ser entendida numa relação "positiva", ou seja, a prática de atividade física resultar em ganhos em relação à saúde, desde que as condições de vida e o contexto do indivíduo sejam "favoráveis" em relação ao acesso a uma educação digna e de qualidade, aos serviços básicos de saúde, aos bens de consumo diversos etc. Entretanto, quando o contexto de vida do indivíduo é "desfavorável", quando não há a disponibilidade de uma alimentação adequada, uma boa moradia, vestimenta, educação que encaminhe o cidadão à alfabetização e à aquisição dos conhecimentos fundamentais/profissionalização, entre tantos outros exemplos, podemos inferir que é muito contraditório afirmar que atividade física geraria saúde (até porque, que saúde é essa?).

São alguns exemplos que mostram a necessidade de complexificar e ampliar

16 Em obra de Gonçalves (1997) são apresentados vários estudos, inclusive brasileiros, que mostram a necessidade de se alargar as compreensões e conclusões em relação às questões que envolvem a prática de atividade física, saúde e doenças - em síntese, pesquisas que exemplificam a necessidade de pensarmos na relação desses elementos a partir da perspectiva da Saúde Coletiva. 
o nosso olhar de professores de EF ao lidar com tais temas.

Sobre isso, também podemos falar sobre as condições de vida e da determinação social da saúde ${ }^{17}$, temas que já começam a apontar para os "caminhos" da Saúde Coletiva.

Segundo Luz (2007, p.20), Saúde

Coletiva pode ser

compreendida como um campo de saberes e de práticas que toma como objeto as necessidades sociais de saúde, com o intuito de construir possibilidades interpretativas e explicativas dos fenômenos relativos ao processo saúde-doença, visando ampliar significados e formas de intervenção.

Em artigo de revisão bibliográfica, Saúde Coletiva: história de uma idéia e de um conceito, Nunes (1994) propõe um resgate da trajetória histórica e conceitual da Saúde Coletiva, campo este oriundos dos projetos preventivistas e da medicina social. Para este autor, a Saúde Coletiva configura-se numa tripla dimensão, ou seja, como corrente de pensamento, como movimento social e como prática teórica. Para ele,

Fundamentando-se na interdisciplinaridade como possibilitadora da construção de um conhecimento ampliado da saúde e na multiprofíssionalidade como forma de enfrentar a diversidade interna ao saber/fazer das práticas sanitárias, a saúde coletiva, no plano concreto dos conteúdos a serem transmitidos, necessita, atualmente, pensar o geral e o específico. Ou seja, sem perder o núcleo central que a legitima e a distingue como área - de saber, de reflexão e crítica do social/coletivo - estar atenta para a formação de determinadas áreas de concentração. Não fugindo da sua vocação, a saúde coletiva - constituída nos limites do biológico e do social ainda continua a ter pela frente a tarefa de investigar, compreender e interpretar os determinantes da produção social das doenças e da organização social dos serviços de saúde, tanto no plano diacrônico como sincrônico da história. $\mathrm{Ou}$, como apontam outros autores, a saúde coletiva ao introduzir as ciências humanas no campo da saúde, reestrutura as coordenadas desse campo, trazendo para o seu interior as dimensões simbólica, ética e política, o que somente poderá revitalizar o discurso biológico. (NUNES, 1994, p.19-20)

\section{Bagrichevsky, Estevão e Palma} (2006) também nos auxiliam a melhor compreender este novo campo. Para eles,

(...) o campo da 'Saúde Coletiva' designa um agregado de saberes e práticas referido à saúde como fenômeno social e, portanto, de interesse público. As origens do movimento de constituição dessa área remontam ao trabalho teórico e político empreendido por pesquisadores de departamentos de instituições universitárias e de escolas de Saúde Pública da América Latina e do Brasil, em particular, ao longo das duas últimas décadas. A profícua atividade desenvolvida no campo científico da Saúde Coletiva deu suporte a um embate político iniciado em meados de 1970, em torno da crise da saúde,

17 Implica em pensar a saúde enquanto objeto das ciências sociais, considerando-se a questão da estratificação social em meio ao padrão de desenvolvimento mundial que tanto contribui à degradação do meio ambiente e da saúde das populações, aumentando as iniquidades pela polarização da renda e de saúde. Assim, a saúde assume uma visão que contempla direitos civis, determinantes econômicos, sociais e ambientais, considerandose esses três fatores: (1) materiais como habitação, alimentação, trabalho, saneamento e outros; (2) psicossociais e comportamentais; (3) biológicos. (ZIONI; WESTPHAL, 2007) 
contextualizada nas lutas ideológicas do país naquele tempo. Esse movimento difundiu-se entre as mais diferentes instâncias organizacionais da sociedade, contribuindo para a formulação e execução de um conjunto de mudanças identificadas como a Reforma Sanitária Brasileira. (p.37)

Em vista dessa apresentação rápida, conceitual e histórica sobre a Saúde Coletiva, e defendendo que são as condições de vida que geram a doença (ou promovem a saúde), e, para isso, considerando os contextos social, ambiental, político, cultural, individual e comportamental como imbricados, responsáveis pelo modo ao qual as pessoas vivem, a Saúde Coletiva amplia o "olhar" sobre as determinações no processo saúde-doença, pois considera aspectos mais amplos da sociedade ao falar de saúde. Não se restringe, portanto, às questões individuais dos "estilos de vida" propagados e adjetivados como "ativos". Ser ativo, neste novo enfoque, é ser comprometido com questões políticas mais gerais, que tenham relação à qualidade do ambiente de vida da comunidade em que se vive.

Amplia-se o olhar sobre tais processos porque passa a considerar o contexto social como determinante na saúde, e aí está uma das questões principais para se entender o que este novo enfoque defende, ou seja, as questões de pertencimento a classes sociais e condições de vida.

Possivelmente, como defendem alguns autores (BAGRICHEVSKY, PALMA,
ESTEVÃO, 2003) pratica atividade física quem já possui um bom estado de saúde e boas condições de vida, diferentemente da grande maioria da população que vive em áreas suscetíveis a maior adoecimento e com nenhum acesso a práticas de lazer - afinal, para se ter lazer, é preciso trabaIho, que gera renda, que gera moradia, boa alimentação etc, e em meio a crescentes "ondas de desemprego", o problema torna-se cada vez maior.

Por isso, entender que o simples discurso monocausal de que "atividade física é saúde" pode não ser efetivo em ambientes os quais não tem água tratada ou sistema de esgoto, onde as prioridades humanas são outras, anteriores à prática de atividade física, com o objetivo de "sobreviver" - alimentar-se, por exemplo, sem a preocupação se tais alimentos que se têm acesso possuem gordura trans ou não, se o valor calórico é alto demais ou não, se a quantidade de sódio está acima dos níveis diários recomendados etc.

Ao atribuir o peso da culpa ou da responsabilidade ao próprio indivíduo, ocorre aquilo que a saúde coletiva denomina de culpabilização da vítima ${ }^{18}$, ou seja, exposto aos vários agravos que o indivíduo sofre no seu dia a dia, seja pelas suas condições de trabalho, de alimentação, de transporte, de relações pessoais, e com o "bombardeio de informações ${ }^{19}$ " que recebe quanto a comportamentos preventivos que deve seguir para "ter saúde", seria "culpa" dele mesmo não seguir o que médicos e

18 Segundo Devide (2002, p.84), este processo "consiste em depositar no cidadão, a responsabilidade por sua saúde individual, ignorando os múltiplos fatores que atuam sobre sua saúde e dos quais ele não possui controle".

19 Fraga (2006, p.24) escreve que "Fazer circular informações sobre os benefícios da vida ativa e os malefícios da vida sedentária passou a ser a arma mais valiosa contra o sedentarismo". Com isso, demonstra que há uma sutil, mas fundamental "inversão de prioridades", ou seja, na chamada "biopolítica informacional", o que parece importar mais é a oferta de informações voltadas à população quanto aos seus "cuidados individuais". 
profissionais da saúde - incluídos aí os professores de EF e os personal trainner - "dizem" ou "recomendam" para ser seguido.

Cabe outro exemplo para ilustrar este caso: vamos pensar em pessoas que acordam às 5 horas da manhã, utilizam de transporte público por duas horas para chegar ao seu local de trabalho, trabalham por cerca de 8 a 10 horas por dia, com uma alimentação não muito adequada, com pressões profissionais (às vezes psicológicas, às vezes físicas) e ainda enfrentam todo esse retorno para casa, chegando completamente esgotadas em seus lares. Como dizer para este sujeito que ele ainda deve sair de sua casa e realizar atividades físicas, já que o que ele mais deseja é recuperar suas energias para o próximo dia de trabalho? (BAGRICHEVSKY, PALMA, ESTEVÃO, 2003; DEVIDE, 1996).

Exemplos dessa relação entre meio ambiente e saúde não faltam, principalmente em relação ao nosso próprio país, de dimensões continentais e com grande diversidade cultural, social e econômica. Um país ao mesmo tempo rico - é uma das maiores economias mundiais, os últimos dados apontam que o Brasil ${ }^{20}$ é a $6^{\mathrm{a}}$ economia mundial, tendo ultrapassado recentemente o Reino Unido - e também pobre - com algumas regiões tendo um índice de desenvolvimento humano próximo aos países mais pobres do mundo. Um país desigual! E essa desigualdade repercute nas condições de vida de uma grande parcela da população que sofre com agravos de doenças tidas como extintas nos países ricos, como por exemplo, a cólera, a dengue, a febre amarela, a hanseníase, entre outras. Portanto, espero ter apresentado mais elementos nesta discussão sobre a relação entre o ambiente em que se vive e a saúde que a população "desfruta", apontando questões para a EF pensar a respeito.

É necessário, além de tudo que já foi apresentado até aqui, considerar o próprio contexto da saúde pública brasileira, mais especificamente o SUS - Sistema Único de Saúde ${ }^{21}$, defendido pela Constituição de 1988 como sendo a saúde um direito do cidadão e dever do Estado. Um sistema de saúde que está baseado em três princípios: a integralidade, a universalidade e a equidade. Trata-se de uma conquista do povo brasileiro que precisa ser aperfeiçoada e meIhorada. Sobre isso, refiro-me ao conceito de empoderamento 22 ("empowerment", segundo BESEN et al, 2007), ou seja, a população tornando-se parte ativa do processo de escolhas das políticas públicas, agindo no

20 O documento A saúde no Brasil, organizado pela Organização Pan-americana de Saúde (1998) apresenta um amplo panorama das condições de saúde prevalentes no país.

21 Como a discussão deste texto não objetiva esmiuçar essa questão, sugiro o artigo de Bagrichevsky \& Estevão (2008), em que os autores tratam da perspectiva da formação profissional em EF tendo como horizonte de atuação o próprio SUS, no Programa Saúde da Família (PSF), intervindo no campo da Saúde Coletiva como educadores e agentes promotores de conhecimentos e práticas corporais éticas em saúde. Outra obra importante para visualizar como a EF pode se inserir no PSF-SUS é a de Freitas (2007), em que a autora discute a intervenção do profissional de EF no serviço público de saúde sob os pontos de vista teórico e prático, trazendo exemplos realizados na cidade de São Paulo.

22 Falar em empoderamento pressupõe pensar o campo da saúde a partir da participação social, ou seja, a Educação em Saúde realizada pelos mais diversos profissionais que compõe este campo multidisciplinar deve articular o trabalho com questões que vão além do biológico, proporcionando o desenvolvimento de conhecimentos, atitudes e comportamentos favoráveis ao cuidado da saúde, não apenas nas condições de vida individuais, mas também na esfera do coletivo, através da consciência política comunitária. (BESEN et al, 2007) 
âmbito de suas próprias comunidades para que os serviços públicos de saúde permitam realmente o acesso a todas as pessoas, na sua universalidade e integralidade, com a equidade (direitos iguais).

Para isso, segundo Farinatti \& Ferreira (2006), Faria Júnior (1992) e Luz (2007), é preciso uma visão desmedicalizada ${ }^{23}$ do processo de saúde, reorganizando saberes científicos com saberes populares, atuando de maneira multi-setorial entre as várias áreas de intervenção, não apenas com os médicos, mas enfermeiros, psicólogos, assistentes sociais, dentistas, e, também, claro, os professores de EF, bem como os demais profissionais constituintes da área da Saúde.

Chegando com a discussão mais especificamente ao campo da EF, apesar de ter realizado constantes aproximações no decorrer do texto, penso ser necessário uma maior complexificação destas temáticas em seu interior, ampliando visões reducionistas, biologicistas, geralmente fragmentadas, e que são hegemônicas, como é o caso da AFRS - aptidão física relacionada à saúde, tendo em autores como Nahas (2003) e Guedes \& Guedes (1993; 1994) seus balizadores, orientando os saberes e práticas às questões individuais da simples atividade física desprovida de elementos contextualizados, no caso, sociais, culturais, econômicos e políticos.

Suas ideias referem-se aos fatores de risco, ou seja, ações que os indivíduos podem "evitar" adotando certas atitudes no seu dia a dica, como não fumar, não ingerir álcool, não comer gorduras, ter comportamentos preventivos (como usar cinto de segurança ou passar pelas faixas de segurança ou mesmo o uso de preservativo nas relações sexuais), entre tantas outras, que podem ser melhor visualizadas, por exemplo, no "pentáculo do bem-estar" (NAHAS, 2003).

Como argumentei no texto, esta visão acaba caindo, também, no que se refere à culpabilização da vítima, pois diz ao indivíduo o que ele deve (ou não) fazer.

No Brasil, a proposta de EF escolar que trabalha com promoção da saúde utiliza os mesmos métodos utilizados nos países de origem dessa proposta, ou seja, atribui-se à EF um compromisso com a promoção à saúde, o qual deve ser de "educar" as pessoas a aderirem à prática regular de exercícios físicos e com isso, torná-las pessoas com estilo de vida ativo e hábitos de vida saudáveis. Isso também não significa, conforme as bases da proposta, que deva ser concretizada através da prática de desportos, nem que os mesmos devam ser excluídos deste processo, apenas redimensioná-los na esfera da educação física escolar. (FERREIRA, 2001).

Aqui no Brasil, o principal agente no binômio atividade física e saúde também é a aptidão física, e conteúdos como o exercício, o desporto e a aptidão física aparecem como conteúdos essenciais da EF. (FERREIRA, 2001). Busca-se, através desses conteúdos, que os alunos pratiquem alguma atividade física, adotem um estilo de vida saudável, e gradualmente, adquiram autonomia (mesmo que mínima) para "praticar essas atividades por conta própria" (Op. cit., p.45). Para isso, acredita-se que transmissão de informações quanto à

23 A idéia da desmedicalização consiste na crítica ao monopólio médico com os cuidados com a saúde, sugerindo que deve haver a cooperação entre áreas para oferecer o melhor serviço de saúde possível, sem hierarquias entre as diversas áreas. 
fisiologia, biomecânica, nutrição e anatomia será fundamental para a compreensão deste processo por parte dos alunos. Este excessivo poder que o indivíduo tem em alterar seu próprio estilo de vida acaba atribuindo a ele uma responsabilidade que na verdade seria do Estado, o qual deveria oferecer condições justas e dignas a seus cidadãos, para que estes soubessem o verdadeiro sentido do que é ser saudável ou ter "qualidade de vida".

De forma alguma se desconsidera o verdadeiro papel do indivíduo em ter uma vida saudável, apenas o que se observa é que ele é o único responsável por tais mudanças, "ignorando" todo o contexto sócio-econômico de um país. Ao se utilizar de um modelo importado, como da América do Norte ou mesmo de países da Europa Ocidental, ignora-se que o conjunto desses países apresenta um índice de desenvolvimento humano (IDH) altíssimo, nas primeiras posições mundiais, enquanto o Brasil ocupa o octogésimo quarto lugar na tabela mundial (conforme dados do PNUD, 2012).

Os profissionais da EF brasileira acabam, então, caindo nessa "causalidade" do exercício físico como promoção à saúde, disseminando a idéia (ingênua) de que quem pratica qualquer atividade física terá saúde (e quem não pratica terá doença), ou que "esporte é saúde" (e as lesões nos atletas de alto nível?). E mais, acabam reduzindo o significado de saúde, quando atribuem à atividade física como fonte de saúde, ora enfocando o senso comum (ou simplista) de que saúde é a "ausência de doença", ora sendo idealista, definindo-a como "estado de completo bem-estar físico, mental e social e não apenas a ausência de doença ou enfermidade" (LEWIS, 1986 apud PALMA, 2001, p.29)
A grande tarefa da EF Escolar, então, é unir os conhecimentos dos determinantes sociais, econômicos, políticos e ambientais (como a história, ecologia, política e sociologia) aos seus conteúdos (os da área biológica, como a anatomia, fisiologia, nutrição e biomecânica), com o objetivo de tornar as pessoas autônomas não só para a prática de exercícios físicos no decorrer de suas vidas, mas também com conhecimento para discernir sobre a realidade em que vivem (FERREIRA, 2001).

Além do mais, a EF brasileira também busca uma melhor identificação quanto àquilo que ela tem a oferecer aos seus alunos, enquanto disciplina escolar, sem perder de vista o contexto real do mundo. Na sua relação com a promoção da saúde, a EF não deve desconsiderar a importância da atividade física (aptidão física), mas não deve fazer com que a prática de exercícios físicos seja apontada como a solução para os demais problemas de saúde. Ela também deve aproveitar esse momento histórico para rever seu papel perante a sociedade, sem esquecer de informar às pessoas que a "melhoria da qualidade de vida depende também das condições básicas de saúde, habitação, renda, trabalho, alimentação, educação etc.". (DEVIDE, 1996, p.50)

\section{DA PATOGENIA À SALUTOGENIA: impli- cações para a EF Escolar}

Acredito que a EF escolar deve incorporar uma outra visão no que se refere à saúde - até porque, na crise de legitimidade que a EF ainda se encontra (BRACHT, 1997), em muito se apóia na saúde para se fazer existir no contexto escolar, quando não faz isso com o esporte - que saia desta visão patogênica para uma visão salutogênica (KUNZ, 2005). 
Taffarel (2010) argumenta que é necessário, aos novos professores de EF, rever e ampliar as questões pertinentes (saberes/práticas/contextualizações) à saúde, complexificando e aprofundando o diálogo a partir das questões sociais e culturais. Conforme tal autora:

O professor de educação física que quiser tratar o tema da saúde nas aulas de Educação Física deve rever seu conceito de 'saúde-doença', de 'cultura corporal-atividade física', de 'escola-objetivo-método-avaliação', de trabalho pedagógico na sala de aula, na escola e no entorno da escola. Deverá compreender a construção sócio-histórica da cultura e agir com uma consistente base teórica sobre o sistema de complexos 'homem-esporte-saúde', que não se restringe ao conhecimento corporal, biológico, aos fatores de risco para a saúde e como preveni-los com 'atividades físicas'. Deverá fazê-lo em perspectiva crítico-superadora conforme proposição defendida pelo Coletivo de Autores (1992). Deverá fazê-lo, não mais idealisticamente e com base na ideologia da higienização e da eugenização, mas sim, na perspectiva emancipatória. (TAFFAREL, 2010, p.179-180)

Segundo Kunz (2005), a visão salutogênica deixa de lado a pergunta "o que causam as doenças", que seria o paradigma patogênico, ligado aos fatores de risco, e prioriza o enfoque na saúde, melhor dizendo, nas condições que mantém a saúde, priorizando os fatores de proteção.

Isso porque, pensando na educação de crianças e jovens ${ }^{24}$, os mesmos não têm preocupação imediata com doenças, em virtude de gozarem de muita saúde, passa despercebido para eles uma "futura preocupação" com agravos de fatores ambientais, por exemplo, até porque os "fatores de risco" referem-se a uma possível realização, baseada em dados estatísticos, a qual pode não acontecer. Desta maneira, não teria sentido para crianças e jovens preocuparem-se, desde cedo, com tais fatores, mas deveria-se, no trabalho pedagógico realizado com eles, se trabalhar os fatores de proteção de saúde ${ }^{25}$, como o sentimento de êxito, de ser bem-sucedido nas atividades, melhorando a auto-estime e o poder de solução de problemas, o encorajamento para ações diferentes das habituais, o movimento corporal numa perspectiva de entendimento de seu próprio corpo (e não em competição com os demais) entre tantos outros que o professor de EF, ao lidar com a cultura de movimento/cultural corporal possibilita espaço de reflexão/ação em suas

24 Aqui falamos em "juventude" embasados em elementos da sociologia da juventude, como Kehl (2003), no texto sobre "A juventude como sintoma da cultura" e Bourdieu (1983), no texto "A 'juventude' é apenas uma palavra". De maneira geral, trata-se de considerar os jovens para além das delimitações e classificações meramente biológicas ou de idade cronológica. Bourdieu (1983) nos alerta que se deve ter o cuidado ao atribuir o conceito de jovem apenas com referência à idade, visto que este dado biológico é socialmente manipulado e manipulável - ao se fazer isso, ou seja, quando atribuímos ao conjunto dos jovens, baseados em uma determinada faixa etária, uma unidade social, com interesses comuns, já estamos homogeneizando esta categoria, deixando de considerar os vários contextos aos quais eles fazem parte, como por exemplo, a questão das condições de vida, do mercado de trabalho, o orçamento do tempo, as questões de classe, entre outras. Já Kehl (2003) argumenta que em nossa sociedade, guiada pela indústria cultural, não podemos falar apenas de um único jovem, integrante de uma única classe social ou apenas daquelas mais favorecidas pelo seu poder de ser consumidor. Em função da publicidade e da televisão, todos os jovens, de todas as classes sociais, são consumidores, embora nem todos (na verdade, poucos) são aqueles capazes de consumir todos os produtos que lhes são oferecidos.

Ver mais em Brodtmann (2006). 
aulas, sem jamais deixar de levar em conta o contexto social, ambiental, cultural e econômico dos alunos sob sua responsabilidade pedagógica.

\begin{tabular}{|c|c|}
\hline Fatores de risco & Fatores de proteção \\
\hline $\begin{array}{l}\text { "Se-movimentar" } \\
\text { robotizado }\end{array}$ & $\begin{array}{l}\text { "Se-movimentar" } \\
\text { livre/autônomo }\end{array}$ \\
\hline $\begin{array}{c}\text { Doença } \\
\text { (Deteção/Cura) }\end{array}$ & $\begin{array}{c}\text { Saúde } \\
\text { (Manutenção/Prevenção) }\end{array}$ \\
\hline Sacrifícios/Dor/Esforço & Prazer/Bem-estar \\
\hline Medicina & Psicossociologia \\
\hline "Estresse" & "Equilíbrio" \\
\hline $\begin{array}{l}\text { (?) } 0 \text { que faz as pessoas } \\
\text { ficarem doentes? }\end{array}$ & $\begin{array}{l}\text { (?) } 0 \text { que mantém a } \\
\text { saúde nas pessoas? }\end{array}$ \\
\hline
\end{tabular}

Figura 1: Do modelo patogênico à possibilidade salutogênica

A figura permite-nos visualizar essa mudança de paradigma ao se pensar as questões da saúde - e não da doença! quando tratamos de tal abordagem na EF. O foco de interesse não recairia nos sempre divulgados "fatores de risco", e sim dar-se-ia ênfase naquilo que realmente promove saúde, ou seja, os "fatores de proteção". A pergunta de partida também mudaria de enfoque, passando do tradicional "O que faz as pessoas ficarem doentes?" para o desafio de pensar "O que mantém a saúde nas pessoas?". O conhecimento que pautaria tal perspectiva salutogênica deixaria de ser aquele exclusivamente médico, dito "modelo biomédico", e consideraria os conhecimentos da psicossociologia, bem como os determinantes sociais da saúde. Em especial ao campo da EF, passaria a se valorizar o se-movimentar autônomo e livre,
De maneira resumida e esquematizada, poderíamos apontar essa mudança paradigmática trazendo a figura 01 abaixo: 
os mais variados temas. Deve-se pensar, portanto, numa formação/atuação crítica, que extrapole falsos cientificismos, como é o caso da causalidade entre exercício físico ser sinônimo de saúde (assim como é também com o esporte).

Como alguém que "cuida de sua casa", a EF escolar deve ter uma preocupação pedagógica mais ampla, de indivíduos que "cuidem de sua sociedade", de seu ambiente de vida, pois é nele que as múltiplas relações sociais ocorrem. E hoje em dia, mais que cuidar apenas de sua própria saúde, é necessário um cuidado com o humano - a humanização na saúde, considerando as desigualdades sociais, por exemplo - $\mathrm{e}$ também com a justiça social. Assim, quem sabe, a EF escolar, sem ser reducionista, passe a exercer seu papel como campo de produção e aplicação do conhecimento que extrapole a esfera individual e da ciência positivista que marcadamente exerce seu poder, rumo a uma visão mais integrada, coletiva, ampla e complexa, contribuindo ao exercício constante da cidadania.

\section{REFERÊNCIAS}

BAGRICHVESKY, Marcos; ESTEVÃO, Adriana. Perspectivas para a formação profissional em Educação Física: o SUS como horizonte de atuação. Arquivos em movimento, Rio de Janeiro, v.4, n.1, janeiro/junho, 2008.

BAGRICHEVSKY, Marcos; PALMA, Alexandre; ESTEVÃO, Adriana; (orgs.). A saúde em debate na Educação Física volume 1. Blumenau: Edibes, 2003.

BAGRICHEVSKY, Marcos; PALMA, Alexandre; ESTEVÃO, Adriana; (orgs.). A saúde em debate na Educação Física volume 2. Blumenau: Nova Letra, 2006.
BAGRICHEVSKY, Marcos; ESTEVÃO, Adriana; PALMA, Alexandre (orgs.). A saúde em debate na Educação Física volume 3. Ilhéus: Editora da UESC, 2007.

BESEN, Candice Boppré; SOUZA NETTO, Mônica de; DA ROS, Marco Aurélio; DA SILVA, Fernanda Werner; GRANDI, Cleci; PIRES, Moacir Francisco. A estratégia Saúde da Família como objeto de Educação em Saúde. Saúde e Sociedade, v.16, n.1, p.57-68, jan./ abr. 2007.

BOURDIEU, Pierre. Questões de sociologia. Rio de Janeiro: Marco Zero, p.112-121, 1983.

BRACHT, Valter. Educação Física e aprendizagem social. $2^{a}$. Edição. Porto Alegre: Magister, 1997.

. Educação Física e ciência: cenas de um casamento (in)feliz. $2^{\text {a }}$. Ed. Ijuí: Unijuí, 1999.

BRASIL, Ministério da Saúde. Secretaria de Vigilância em Saúde. Impacto da violência na saúde dos brasileiros. Brasília: Ministério da Saúde, 2005, 340p.

BRODTMANN, Dieter. "O que mantém as crianças e os jovens mais saudáveis?" Novas maneiras de entender a saúde e suas conseqüências na promoção e educação. In: KUNZ, Elenor. Educação Física crítico-emancipatória: com uma perspectiva da pedagogia alemã do esporte. ljuí: Unijuí, p.97-115, 2006.

CARVALHO, Yara Maria de. Atividade física e saúde: onde está e quem é o "sujeito" da relação? Revista Brasileira de Ciências do Esporte, vol.22, n.2, p.9-21, janeiro 2001. . 4a. Ed. O 'mito' da atividade física e saúde. São Paulo: Hucitec, 2009. 
DARIDO, Suraya Cristina. Os conteúdos da Educação Física escolar: influências, tendências, dificuldades e possibilidades Perspectivas em Educação Física Escolar, Niterói, v. 2, n. 1 (suplemento), 2001.

DEVIDE, Fabiano Pries. Educação Física e saúde: em busca de uma reorientação para a sua práxis. Movimento, Porto Alegre, ano III, n.5, 1996/2, p.44-55.

. Educação Física, qualidade de vida e saúde: campos de intersecção e reflexões sobre a intervenção. Movimento, Porto Alegre, vol.8, n.2, maio/agosto 2002, p.77-84.

FARIA JÚNIOR, Alfredo. Dossier Educação Física, desporto e promoção da saúde. Horizonte, 9(51), I-VIII, set./out. 1992. FARINATTI, Paulo de Tarso Veras; FERREIRA, Marcos Santos. Saúde, promoção da saúde e educação física: conceitos, princípios e aplicações. Rio de Janeiro: EdUERJ, 2006.

FERREIRA, Marcos Santos. Aptidão física e saúde na educação física escolar: ampliando o enfoque. Revista Brasileira de Ciências do Esporte, vol.22, n.2, p.41-54, janeiro 2001.

FRAGA, Alex Branco. Exercício da informação: governo dos corpos no mercado da vida ativa. Campinas: Autores Associados, 2006.

FRAGA, Alex Branco; WACHS, Felipe. Educação Física e saúde coletiva: políticas de formação e perspectivas de intervenção. $2^{\mathrm{a}}$ ed. Porto Alegre: Editora da UFRGS, 2007.

FREITAS, Fabiana Fernandes de. A Educação Física no serviço público de saúde. São Paulo: Hucitec, 2007.

GIDDENS, Anthony. Sociologia. $5^{\mathrm{a}}$ ed. Porto Alegre: Artmed, 2005.
GOMES, Ivan Marcelo. Conselheiros modernos: propostas para a educação do indivíduo saudável. Brasília: Thesaurus/CBCE, 2009, 292p. (formato digital)

GONÇALVES, Aguinaldo. Para quê a saúde coletiva na educação física? Reflexões de profissional na área há vinte anos. Revista da Educação Física/UEM, Maringá, v. 15, n. 1, p. 89-93, 1. sem. 2004.

GONÇALVES, Aguinaldo (org.). Saúde coletiva e urgência em Educação Física e Esportes. Campinas: Papirus, 1997.

GUEDES, Claudia Maria. A educação física e os mistérios de seu tempo. Revista Brasileira de Ciências do Esporte, vol.21, n.2/3, jan./maio 2000.

GUEDES, Dartagnan Pinto; GUEDES, Joana Elisabete Ribeiro Pinto. Educação Física escolar: uma proposta de promoção da saúde. APEF, Londrina, v.7, n.14, janeiro/93a, p.16-23.

- Subsídios para implementação de programas direcionados à promoção da saúde através da Educação Física escolar. APEF, Londrina, v.8, n.15, 1993b, p.3-11.

Sugestões de conteúdo programático para programas de Educação Física Escola direcionados à promoção da saúde. APEF, Londrina, v.9, n.16, 1994a, p.3-14.

. Implementação de programas de Educação Física escolar direcionados à promoção da saúde. Revista Brasileira Saúde escolar, 3 (1-4), 1994b, p.67-74. $\mathrm{KEHL}$, Maria Rita. A juventude como sintoma da cultura. In: NOVAES, Regina \& VANNUCHI, Paulo. Juventude e sociedade - trabalho, educação, cultura e participação. São Paulo: 
Instituto Cidadania/Editora Perseu Abramo, p. 89-114, 2003.

KUNZ, Elenor. "Ministério da saúde adverte: viver é prejudicial à saúde". In: XV Congresso Brasileiro de Ciências do Esporte, 15 a . Ed. Anais... Porto Alegre, CBCE, 2005.

LUZ, Madel T. Novos saberes e práticas em saúde coletiva: estudo sobre racionalidades médicas e atividades corporais. $3^{a}$. Ed. São Paulo: Hucitec, 2007.

MINAYO, Maria Cecília de Souza. Interdisciplinaridade: funcionalidade ou utopia? Saúde e Sociedade, v.3, n.2, p.42-64, 1994.

NAHAS, Markus Vinícius. Atividade física, saúde e qualidade de vida. Londrina: Midiograf, 2003.

ORGANIZAÇÃO PAN-AMERICANA DE SAÚDE. Escritório de Representação no Brasil. A saúde no Brasil. Brasília: novembro/1998.

PALMA, Alexandre. Atividade física, processo saúde-doença e condições sócio-econômicas: uma revisão de literatura. Revista Paulista de Educação Física, São Paulo, 14(1), 97-106, jan./ jun. 2000.

- Educação Física, corpo e saúde: uma reflexão sobre outros "modos de olhar". Revista Brasileira de Ciências do Esporte, Campinas, v.22, n.2, p.2339, jan./2001.

PROGRAMA DAS NAÇÕES UNIDAS PARA O DESENVOLVMENTO - PNUD. Atlas do desenvolvimento humano - Brasil. Disponível em: < http://www.pnud. org.br/atlas/> . Acesso em: 20 fev. 2012. RODRIGUES, Anegleyce Teodoro. A questão da formação de professores de Educação Física e a concepção de professor enquanto intelectualreflexivo-transformador. Pensar a Prática, Goiânia, vol. 1, 1998.

SOARES, Carmen. Educação Física: raízes européias e Brasil. $4^{\mathrm{a}}$ ed. Campinas: Autores Associados, 2007.

TAFFAREL, Celi Zulke. Sobre o sistema de complexos homem-esporte-saúde: reflexões a partir de contribuições da Alemanha. In: MATIELLO JUNIOR, Edgard; CAPELA, Paulo; BREILH, Jaime. Ensaios alternativos latino-americanos de Educação Física, Esportes e Saúde. Florianópolis: Copiart, p.159-183, 2010.

ZIONI, Fabiola; WESTPHAL, Márcia Faria. $\mathrm{O}$ enfoque dos determinantes sociais de saúde sob o ponto de vista da teoria social. Saúde e Sociedade, São Paulo, v.16, n.3, p.26-34, 2007. 
EXTENDING THE LOOK ON HEALTH IN PHYSICAL EDUCATION SCHOOLAR: critiques and possibilities in dialogue with the theme of the environment from the Public Health

\begin{abstract}
This paper proposes a reflection about the health issues in Physical Education Schoolar (PES), expanding to look at this historical relationship and deserves, in our present time, more in-depth considerations of PE teachers and unicausal exceeding the plan by example, the idea that physical activity leads to health automatically. Approaches to such issues from the grounds of "public health" in an attempt to bring elements of PE with the Social Sciences/Humanities, with some implications for the PES, especially the change of focus/paradigm, leaving the plane pathogenic toward the possibilities with salutogenia.

Keywords: Health; Physical Education Schoolar; vocational training in Physical Education.
\end{abstract}

Recebido em: março/2012

Aprovado em: julho/2012 